\title{
NO ENTREMEIO DO FUNCIONAMEMTO DO DISCURSO DO CORDEL: O RITMO E A ESTEREOTIPIA
}

\author{
Fernanda Moraes D’Olivo* \\ Suzy Lagazzi*
}

RESUMO: Este artigo apresenta uma análise do funcionamento da estereotipia e do ritmo na literatura de cordel. Tomamos como fundamentação teórica e metodológica a Análise de Discurso materialista. Para a constituição do corpus discursivo utilizamos folhetos nordestinos que retratam a figura feminina. Esses folhetos se encontram no acervo de Literatura de Cordel do CEDAE/UNICAMP. Compreendemos, nesta análise, que o entrecruzamento entre o ritmo e a estereotipia produz um efeito de ludicidade que permite que a moral, constitutiva dos discursos do cordel, circule mais facilmente entre os interlocutores.

Palavras-chave: Análise de Discurso; ritmo; estereótipo; cordel

\section{INTRODUÇÃO}

Quando ouvimos falar em Cordel, ligamos tal palavra às imagens de livros pequenos, feitos de um material bem simples, com um desenho na capa representando o conteúdo do texto, pendurados em cordões ou expostos em bancas nas feiras populares do nordeste para serem comercializados. Ao pegarmos um desses "livrinhos" parece que, a cada verso, começamos a ouvir os próprios autores recitando tais pala-

* IEL/UNICAMP 
vras. Vemos, através dos personagens representados nos cordéis, a personificação de várias figuras que nos fazem pensar em uma parcela do povo nordestino, com sua força e jogo de cintura para sobreviver.

Os primeiros desses livretos foram produzidos por trabalhadores rurais com quase nenhuma educação formal, que escreviam para um público também distanciado da educação formal. Tanto os cordelistas quanto o seu público sempre foram muito identificados com os preceitos morais da Igreja e com o regime patriarcal. Os autores de cordel buscavam representar a comunidade onde eles viviam através de versos que traziam temas do cotidiano ou histórias fantásticas. Essas histórias, dispostas no cordel em versos ritmados, perdem muito da sua beleza se forem lidas apenas em voz baixa. O cordel é feito para ser recitado.

O processo de recitação nos folhetos é importante, pois tal literatura vem de uma tradição oral e na sua forma escrita há a marca dessa oralidade. Os poetas usam a recitação dos poemas como atrativo principal para sua circulação e comercialização. Houaiss (1979), no prefácio para o livro Cordel, do encantamento às histórias de luta, comenta a relação da oralidade com a Literatura de Cordel:

Nessa síntese - menos descritiva que indagativa - há que ressaltar o convívio perdurante da literatura oral com a literatura de cordel, a partir do advento desta. Esta se baseia na primeira, mas nem por isso a primeira, oral, deixa de subsidir, já que o cordel desde sempre aspira ser 'ouvido', constituindo a forma impressa um meio de expansão da oralidade. (p.15)

Os versos do folheto não são apenas lidos em voz alta, mas sim recitados com um ritmo próprio, proporcionado pela rima e pela métrica, ambas bem marcadas e contínuas, que ajudam na memorização dos versos dos cordéis: 
S aber, por exemplo, que o segundo, quarto e sexto versos terminarão com um mesmo som permite prever minimamente o que será dito e auxilia a recordação de uma história já conhecida. A regularidade fornece marcas, 'pistas', sobre o caminho que a composição seguirá, não só com quem a apresenta, mas também para quem a ouve". (ABREU, 1999: 88)

A partir da reflexão de Abreu (1999), podemos afirmar que os indivíduos que se reúnem em volta do recitador para ouvir os poemas são contagiados pelo movimento de repetição de estrutura(s) padrão(ões) dos folhetos e, nesse sentido, queremos ressaltar a presença do ritmo nos cordéis. S e o cordel fugir dessa estruturação esperada será menor a facilidade de guardá-lo na memória. Isso é posto no seguinte trecho de Houaiss (1 979) sobre o cordel: “... pois parece âmbito de consumo voluntário em que o marketing se afunda e o que não "pega" - por não interessar ao seu público - não se reimprime e não vinga..." (p. 16). Os cordelistas trabalhavam e ainda trabalham dentro de um espaçojá estabelecido, cuja ruptura, se por um lado poderia permitir uma maior liberdade de formulação para o autor, por outro lado pode afetar o interesse do público, se vier a comprometer o processo de recitação. Ressaltamos que o ritmo é muito importante no processo de circulação dos cordéis.

Mas, como já dissemos, não é só o ritmo que chama a atenção quando lemos os folhetos, os personagens também chamam. Eles são representados no cordel de forma estereotipada, mostrando características de parte do povo nordestino ou de pessoas específicas que fazem parte de populares histórias ou da comunidade em que o cordelista vivia, características estas estabilizadas socialmente. S obre a estereotipia, a sociologia e a psicologia apresentam tal conceito como sendo constituído por uma idéia pré-formada e simplificada que se impõe como sendo fixa dos membros de uma coletividade ou de cada indivíduo. Complementando essa explicação, Amossy \& Herschberg Pierrot (1997) dizem que o estereótipo 
é "Fonte de erros e de preconceitos, ele aparece também como um fator de coesão social, um elemento construtivo no relacionamento consigo mesmo e com o Outro" (p: 43) ${ }^{1}$. Parece-nos importante chamar a atenção para o fato de a estereotipia estar presente nas relações sociais, tendo um papel marcante na circulação dos versos dos cordéis.

Percebendo esta forte relação do estereótipo e do ritmo com a própria constituição do Cordel, interessou-nos compreender como o ritmo e a estereotipia funcionam no processo de circulação de sentidos dos discursos presentes nos folhetos. Devido à variedade temática, optamos por analisar os discursos sobre a figura feminina representada nessa literatura, sendo este o nosso recorte do material de trabalho.

\section{A ANÁLISE DO DISCURSO NA COMPREENSÃO DO FUNCIONAMEN- TO DO RITMO E DO ESTEREÓTIPO NA LITERATURA DE CORDEL}

Para responder a questão posta acima, tomamos o dispositivo teórico-analítico da Análise de Discurso (AD) de perspectiva materialista, fundada na década de 60 por Michel Pêcheux, que busca compreender os efeitos de sentido que estão presentes nos discursos e explicitar o funcionamento discursivo.

Analisamos a estereotipia mobilizando os conceitos de memória discursiva e de pré-construído. Os estereótipos são configurados por sentidos que sustentam uma determinada discursividade, fazendo parte da instância da memória discursiva. Entendemos esses sentidos como sendo o pré-construído, que, nas palavras de Pêcheux (1975), é “o

\footnotetext{
1 Tradução própria. Trecho original: "S ource d'erreurs et de préjuges, il apparaît aussi comme un facteur de cohésion sociale, un élément constructif dans la rapport à soi et à l'Autre." (p. 43)
} 
que remete a uma construção anterior, exterior, mas sempre independente, em oposição ao que é 'construído' pelo enunciado" (p. 99). Nossas compreensões acerca da relação entre pré-construído e estereotipia tiveram como ponto de partida a relação desses dois conceitos feita por Amossy e Hersheberg Pierrot (1997), acima referida. S egundo as autoras, o estereótipo - idéia pré- estabelecida e pré-afirmada pelo sujeito e/ ou grupo social sobre determinadas temáticas - pode ser relacionado com o 'pré- construído', porque este concebe o sujeito interpelado na linguagem, na qual o préafirmado comanda o que ainda está para se afirmar, produzindo um efeito de verdade imediata. Trazendo essa concepção para o quadro teórico discursivo, diremos que o estereótipo é uma "representação" do imaginário social, sendo que a representação, para a $\mathrm{AD}$, não se constitui numa relação direta entre palavras e coisas, linguagem e mundo, e, justamente por isso, sempre falamos que representação é imaginária.

Para uma análise do ritmo precisamos delimitá-lo, pois ele é um elemento de linguagem que pode ser analisado de diversas maneiras, como por exemplo, a análise prosódica feita pela fonética. Vamos concebê-lo como uma repetição ritmada, produzida pela estrutura da rima e pelo jogo entre as palavras, trabalhando para organizar o discurso e produzindo sentidos resultantes dos movimentos rítmicos (Meschonnic, 1982). Assim, tomamos o ritmo no cordel como um elemento fundamental no trabalho da circulação da discursividade presente nos folhetos.

\section{MATERIAL DE PESQUISA E CONSTITUIÇÃO DO CORPUS DISCURSIVO}

Nosso material de análise é composto por cordéis que fazem parte do acervo de Literatura de Cordel pertencente ao 
CEDAE/UNICAMP². Estimamos, baseando nos no período de produtividade dos autores dos folhetos escolhidos para análise, que esses cordéis foram produzidos entre a década de 50 e $70^{3}$. Os folhetos são os seguintes: $O$ valor da mulher; Discussão de Amaro Quaresma e José Batista; A mulher linguaruda, Nascimento, vida e morte de uma coroa; A mulher que se casou dezoito vezes; Os sinais das mulheres, A mulher do compadre Nicolau.

O corpus, na Análise de $\mathrm{D}$ iscurso, tem um caráter dinâmico e o seu fechamento só se dá com o final das análises. Para analisar o corpus nos orientamos pelas condições de produção (relação, não direta, entre o lugar em que o sujeito está inscrito e o ambiente material e institucional em que o discurso é produzido), importantes para se chegar às generalizações e às regularidades, sem o perigo de apagar a polissemia e os funcionamentos discursivos constitutivos desses cordéis. Para a compreensão da nossa questão, nos centramos em folhetos que apresentavam alguns estereótipos femininos e, a partir desses cordéis, fizemos recortes que nos permitiam observar o funcionamento discursivo do ritmo e da estereotipia para compreendermos os efeitos de sentido desse funcionamento.

\section{O FUNCIONAMENTO DA ESTEREOTIPIA E DO RITMO}

Nosso corpus é constituído por folhetos nos quais há a representação de estereótipos femininos tanto positivos quanto negativos ${ }^{4}$, sendo que estes últimos apresentam um tom pe-

2 O CEDAE (C entro de D ocumentação Alexandre E ulálio) é um centro de documentação onde são arquivados acervos literários, materiais de pesquisa, entre outros. O CEDAE está localizado no Instituto de Estudos da Linguagem (IEL), na Universidade Estadual de Campinas (Unicamp).

3 Não temos as datas exatas de produção dos folhetos devido ao fato que eles não as apresentarem impressas nos livretos.

4 Pensamos em classificar os estereótipos em positivos ou negativos, baseandonos no que a sociedade considera bom ou ruim em relação à figura da mulher. 
jorativo. Durante as nossas primeiras observações dos recortes, chamou-nos a atenção o fato de que esses estereótipos têm seus sentidos formulados por uma discursividade marcada por preceitos morais que circulam na sociedade. E ntendemos que essa moral dá base aos sentidos dos estereótipos, determinando-os no discurso do cordel.

Para dar visibilidade ao funcionamento da moral nos folhetos, analisamos os cordéis realizando uma divisão em relação às imagens femininas que fazem parte do nosso corpus:

- Grupo dos estereótipos que seguem um padrão social desejado: fazem parte desse grupo os estereótipos femininos que se encaixam no ideal de mulher pensado pela sociedade para a qual o cordel é feito. E ncontramos nesse agrupamento as figuras da boa esposa, da mulher perfeita e da mulher obediente e submissa ao pai ou ao marido.

- Grupo dos estereótipos que não seguem um padrão legitimado socialmente: Classificamos nesse grupo as imagens das mulheres que fogem aos padrões sociais de uma mulher ideal, padrões estes sustentados pela moral. C omo exemplo dessas figuras temos a imagem da "coroa", da "mulher linguaruda" e da "mulher-macho".

Nos seguintes trechos, podemos observar as imagens femininas representadas no primeiro grupo:

\section{Figura da esposa:}

"Bastará para haver grande harmonia/ Cada casa ter dentro uma mulher/ Pois não há casa alguma com mister/ S e faltar lhe a mulher para alegria/ S e a mulher faz nascer à poesia/ S em mulher não há gosto nem vantagem/ S em mulher nem um homem tem coragem/ S em mulher não há festa nem brinquedo/ S em mulher todo 
riso finda cedo/ Sem mulher vive o homem sem imagem." (trecho do cordel $O$ valor da mulher)

"A- Hoje em dia sou casado/ Mas não estou arrependido/ Não sou lá tão bom marido/ Mais dou conta do recado/ Já tenho filho criado/ Mas acho que me convêm/ Em casa de tudo tem/ Não me falta o que comer/ Pois é este o meu prazer/ S em mulher não sou ninguém// A- S em mulher nada me graça/ S em mulher só vive triste/ S em mulher ninguém resiste/ S em mulher homem não passa/ S em mulher tudo embaraça/ Sem mulher não me dou bem/ Sem mulher quero morrer/ S em mulher não há prazer/ Sem mulher não sou ninguém". (trecho do cordel Discussão de Amaro Quaresma e José Batista)

"Se não houvesse mulher/ Era preciso fazê-la/ Uma casa sem mulher/ Não há quem deseje vê-la/ É como um dia sem sol/ E uma noite sem estrela". (trecho do cordel Os sinais das mulheres)

\section{Mulher delicada e bela:}

"É de acordo que o homem trate bem/ Da mulher que viver-lhe em companhia/ Para dar a beleza e a primazia/ Que a mulher bem decente sempre tem/ Se a mulher é o ente que convém/ Que o perfume das rosas viva nela/ Deverá ser tratada com cautela/ Para assim não perder sua beleza/ Pois que a mão da Divina Natureza/ Quando fez a mulher foi para ser bela// Compreendo que Deus interessou-se/ Em fazer a mulher com perfeição/ Pois fazendo a primeira para Adão/ Deu-lhe muita candura e um riso doce/ Pois ao vê-la Adão logo contentou-se/ E achou logo o mundo menos triste; / Já por isto é que o homem não resiste/ Os carinhos e agrados da mulher; / E a mulher fará tudo 
que quiser/ Por ser ela o melhor anjo que existe". (trecho do cordel $O$ valor da mulher)

\section{Mulher submissa:}

"Mostra sempre a mulher bom coração/ Quando sofre os maus tratos dum marido". (trecho do cordel $O$ valor da mulher)

"A mulher vivia bamba/ De todo dia apanhar/ Mas na frente do marido/ Não ousava reclamar/ Por ser tímida e bondosa/ Que nem se chega a pensar/ / No café ela apanhava/ Antes de lavar o rosto/ Quando ela ia para a roça/ D ava- lhe tremendo encosto/ Que a pobre ficava troncha/ Mas não deixava o seu posto". (trecho do cordel $A$ mulher do compadre Nicolau)

Através desses excertos, observamos a presença do efeito do pré-construído moral trabalhando para sustentar os sentidos desses estereótipos. Dizeres como "Bastará para haver grande harmonia / Cada casa ter dentro uma mulher/ Pois não há casa alguma com mister/ Se faltar lhe a mulher para alegria"; "Uma casa sem mulher/ Não há quem deseje vê-la/ É como um dia sem sol/ E uma noite sem estrela"; "Compreendo que Deus interessou-se/ Em fazer a mulher com perfeição/ Pois fazendo a primeira para Adão/ Deu-lhe muita candura e um riso doce"; "Mostra sempre a mulher bom coração/ Quando sofre os maus tratos do marido"; "A mulher vivia bamba/ De todo dia a panhar/ Mas na frente do marido/ Não ousava reclamar (...)// Mas não deixa va o seu posto" nos mostram proposições acerca da figura feminina que tem seus sentidos já reafirmados na sociedade pelo imaginário social da mulher legitimada estética e moralmente. Os enunciados que trazemos acima constituem um processo de reafirmação das características femininas esperadas pela sociedade. Isso fica visível pela relação estabelecida entre a delicadeza da mulher 
e a criação divina, entre a ligação esperada da mulher e do bem estar do lar e da obediência feminina ao marido diante de qualquer situação, até mesmo dos maus tratos do marido. São essas características, baseadas em pré-construídos morais de mulher delicada, de boa esposa e de mulher obediente ao homem, que configuram os estereótipos de mulher considerados bons pela sociedade e que ao mesmo tempo endossam os pré-construídos morais que constituem o imaginário popular da figura feminina desejada.

Os estereótipos femininos que não seguem um padrão social se constituem e se significam na contraposição das imagens femininas idealizadas socialmente. Ou seja, eles funcionam na oposição em relação aos pré-construídos morais que sustentam os estereótipos desejados pela sociedade. Observamos essa relação de contraposição nos seguintes trechos:

\section{Mulher faladeira}

"Uma mulher faladeira/ É uma viagem sem ter porto,/ É trabalho sem descanso,/ É viúva sem conforto/ Trabalhador sem salário,/ Peixe fora do Aquário/ É urubu sem ter morto!...// Mulher da língua comprida/ É açúcar no feijão,/ É beber café com sal,/ É raiva no coração.../ É condutor sem trocado,/ Bodegueiro no fiado/ É carro na contra-mão!//A mulher que é faladeira/ É professor sem aluno,/ Réu sem ter Advogado, / É tribunal sem tribuno.../ Viúva sem proteção,/ É playboy sem medalhão/ Pedra pra gatuno!(...)" (trecho do cordel $A$ língua da mulher faladeira).

\section{A coroa}

"Quem quiser viver em paz/ Se afaste de uma coroa/ Parece que elas todas/ Ou da bonita ou boa/ Carregam o diabo nas costas/ Que até o diabo se acoa.// Coroa é uma rama/ Que nasce duma mulher/ Pois só 
existe coroa/ Porque nasceu Lúcifer/ C oroa é uma maldita/ Não meto a minha colher (...)/ / De 18 aos 25/ Tem a oportunidade/ D e encontrar o paletó/ Ou a dura realidade/ $\mathrm{D}$ e ir para o inferno/ Com toda a sua maldade (...)/ / A partir dos 33/ Começa o desespero/ Desacredita nos santos/ Vai frequentar o terreiro/ Fazendo uma salada/ Com padre e macumbeiro.// Dos 33 aos 40/ É a fase dos nos acuda/ Vai a São Paulo atrás/ De um marido pra muda/ Mas lá não o encontrando/ Uma nova trama estuda.// Nessa idade a mulher/ É fera imprevisível/ Anda atrás de um Adão/ Que lhe queime o fusível/ Nessa idade ela casa/ Com qualquer homem sofrível..." (trecho do cordel Nascimento vida e morte de uma coroa).

\section{Mulher-macho}

"Laça boi, mata cavalo, / D erruba touro "Pereira", / Mulher-Macho, sinsenhor!.../ Usa punhal e peixeira,/ Luta B ox e joga bola, / Numa briga mata, esfola, / Sabe jogar capoeira!... (...)// Levará para a capela, / E mandará dizer missa!... / Chorará fingidamente, / Clamando aos céus por justiça,/ Tantos maridos valentes, / Motoristas competentes, / S eu carro não desenguiça!... (...)/ / Mas em cada sepultura,/ Há de deitar uma flor,/ Dizendo, -Durma feliz, / Ó meu décimo oitavo amor!.../ Que a terra te seja leve,/ E outro irá muito breve,/ Aliviar tua dor!... (...)// Na capela Dorotea/ Fará sua devoção!/ Diante da sua Santa,/ Virgem da recordação, / E dirá a meia voz/ E stou virgem como vós, / C omo doe meu coração!..." (trecho do cordel $A$ mulher que se casou dezoito vezes).

Por meio dos recortes apresentados acima, podemos observar que na configuração dos três estereótipos há um efeito de deboche. Esse efeito é produzido, no caso da mulher 
faladeira, por meio da comparação desta com a ausência do essencial (Uma mulher faladeira/ É uma viagem sem ter porto,/ É trabalho sem descanso,/ É viúva sem conforto/ Trabalhador sem salário,/ Peixe fora do Aquário/ É urubu sem ter morto!) e com o cúmulo do ruim (Mulher da língua comprida/ É açúcar no feijão, / É beber café com sal, / É raiva no coração... É condutor sem trocado,/ Bodegueiro no fiado/ É carro na contra-mão!"); no caso da 'coroa', pela própria nominalização desta ('coroa'), que tem um apelo a uma sexualidade mal resolvida pela falta do casamento; e, em relação à mulher macho, notamos que as marcas discursivas relacionadas à fibra da personagem do folheto e a sua não possibilidade de perder a virgindade com os seus maridos, devido às suas mortes antes da noite de núpcias, é o que provocam um efeito de deboche no discurso: deboche da mulher de fibra (mulher-macho), que não responde à expectativa imaginária de uma mulher delicada, deboche da mulher linguaruda que não corresponde à imagem da mulher discreta, e deboche da coroa que não segue o padrão desejado socialmente de uma boa moça que deve estar casada até uma determinada idade.

Esses três estereótipos se significam na negação das imagens desejadas socialmente, imagens estas que são pautadas em pré-construídos morais, conforme já dissemos anteriormente. Por meio do deboche, que traz um tom pejorativo ao discurso, e da negação dos estereótipos idealizados socialmente por esses estereótipos, observamos a presença dos pré-construídos morais na sustentação dos estereótipos femininos que não seguem os padrões desejados pela sociedade.

Mas, como os discursos dos cordéis, tendo os preceitos morais como elementos pré-construídos dos seus sentidos, circulam tão facilmente entre os interlocutores? Aí é que entra o funcionamento do ritmo.

Os estereótipos que seguem os padrões desejados socialmente e os que fogem às expectativas do imaginário social em relação às mulheres circulam através de um discurso ritmado, produzido pela estruturação das rimas e da métrica, 
que podem ser observadas no texto escrito, mas ficam mais visíveis durante o processo de recitação dos cordéis. A métrica e os esquemas de rimas são regulares ao longo de todos os cordéis, configurando, dessa maneira, um ritmo constante. Os folhetos são estruturados, quanto à métrica, geralmente em sextilhas ou sete sílabas e, quanto ao esquema de rima, ele é sempre regular, ou seja, se na primeira estrofe temos o esquema $\mathrm{ABCBDB}$, as estrofes seguintes seguirão a mesma estrutura. Essa estruturação dos versos e das estrofes do cordel é que garante o seu movimento rítmico. Para darmos visibilidade à produção no ritmo nos folhetos, apresentamos, abaixo, alguns excertos:

\begin{tabular}{|c|c|c|}
\hline $\begin{array}{l}\text { A mulher do } \\
\text { compadre Nicolau }\end{array}$ & $\begin{array}{l}\text { Agora eu vou contar A } \\
\text { Uma estória que me contou B } \\
\text { Minha mãe, um certo dia C } \\
\text { E hoje agora, eu vou B } \\
\text { Contar para vocês D } \\
\text { Como o meu cérebro lembrou: B }\end{array}$ & $\begin{array}{l}\text { Havia nesse sertão A } \\
\text { Que todo mundo conhece B } \\
\text { Um casal desunido C } \\
\text { Que a ninguém apetece B } \\
\text { Por culpa mais do marido C } \\
\text { Que nessa estória aparece B }\end{array}$ \\
\hline $\begin{array}{lrr}\text { Discussão } & \text { de } & \text { Amaro } \\
\text { Quaresma } & \text { e } & \text { José } \\
\text { Batista } & & \end{array}$ & $\begin{array}{l}\text { A- Eu quando era solteiro A } \\
\text { Só vivia aperriado B } \\
\text { Nunca me vi descansado B } \\
\text { Trabalhava o ano inteiro A } \\
\text { Hoje não tenho dinheiro A } \\
\text { Mas me sinto muito bem C } \\
\text { Muitos sozinhos que tem C } \\
\text { Fortuna e vive isolado B } \\
\text { Hoje em dia eu sou casado B } \\
\underline{\text { Sem mulher não sou ninguém C }}\end{array}$ & $\begin{array}{l}\text { A- Hoje em dia sou casado A } \\
\text { Mas não estou arrependido B } \\
\text { Não sou lá tão bom marido B } \\
\text { Mais dou conta do recado A } \\
\text { Já tenho filho criado A } \\
\text { Mas acho que me convêm C } \\
\text { Em casa de tudo tem C } \\
\text { Não me falta o que comerD } \\
\text { Pois é este o meu prazerD } \\
\text { Sem mulher não } \\
\text { ninguém C }\end{array}$ \\
\hline
\end{tabular}




\begin{tabular}{|c|c|c|}
\hline O valor da mulher & $\begin{array}{l}\text { Um dia eu estava liso A } \\
\text { Sem ter nada que almoçar B } \\
\text { Quando a mulher dum doutor C } \\
\text { Mandou a mim convidar B } \\
\text { Para cantar um pouquinho D } \\
\text { Para ela apreciar B }\end{array}$ & $\begin{array}{l}\text { A mulher é um anjo sem } \\
\text { segundo A } \\
\text { É a luz que melhor beleza } \\
\text { encerra B } \\
\text { Sem mulher todo homem } \\
\text { nesta terra B } \\
\text { Detestava os prazeres deste } \\
\text { mundoA } \\
\text { Pois a terra seria um vácuo } \\
\text { fundoA } \\
\text { Se faltasse a mulher que nela } \\
\text { habita C } \\
\text { Sem mulher toda terra era } \\
\text { esquisita C } \\
\text { Sem mulher não havia riso e } \\
\text { festa D } \\
\text { Sem mulher neste mundo } \\
\text { nada presta D } \\
\text { Se mulher é a prenda mais } \\
\text { bonita C }\end{array}$ \\
\hline $\begin{array}{l}\text { A língua da mulher } \\
\text { faladeira }\end{array}$ & $\begin{array}{l}\text { Existe mulher no mundo A } \\
\text { Que tem a língua comprida B } \\
\text { Igual a légua de beiço C } \\
\text { Porque leva a sua vida B } \\
\text { A falar de Deus e o mundo, A } \\
\text { Mas a mulher de Raimundo A } \\
\text { Essa passa da medida B } \\
\text { Raimundo Praxedes Braga A } \\
\text { Morador de Amaralina B } \\
\text { Tem a mulher que parece C } \\
\text { O raio da silibrina, B } \\
\text { Fala do fogão, fala da brasa, D } \\
\text { Das telhas de sua casa, D } \\
\text { Do banheiro, da sentina. B }\end{array}$ & $\begin{array}{l}\text { Que a filha é preguiçosa, A } \\
\text { Que os vizinhos são ruins, B } \\
\text { Que a mãe dela é sebosa, A } \\
\text { Que a rua dela não presta, D } \\
\text { Que a sogra é desonesta, D } \\
\text { A madrinha é vaidosa. A } \\
\text { Julia fala de Totonha, A } \\
\text { De Chica, de Damiana, B } \\
\text { De Quitéria, de S ofia, C } \\
\text { De Zefinha e de Caetana, B } \\
\text { Fala do pai Maroca, D } \\
\text { Fala da mãe de Finoca, D } \\
\text { Do filho de Mariana. B }\end{array}$ \\
\hline
\end{tabular}


Compreendemos aqui, por meio da própria estrutura poética do cordel, que o ritmo funciona nesse discurso produzindo, através das repetições ritmadas, um efeito de brincadeira em forma de jogo de linguagem, o que imprime, juntamente com os estereótipos, um efeito de ludicidade à moral que circula no discurso dos folhetos, permitindo que a circulação da moral e, consequentemente, do discurso do cordel, se dê de uma maneira mais naturalizada, com menos resistência por parte dos interlocutores. O efeito de ludicidade, portanto, é produto do jogo que há entre a estereotipia e o ritmo. Esses três elementos funcionam no sentido de fazer com que os preceitos morais sejam reafirmados para o público numa forma artística e não como claramente algo imposto, conforme acontece nos sermões das igrejas, por exemplo.

\section{CONSIDERAÇÕES FINAIS}

A análise apresentada neste artigo nos permitiu compreender o papel fundamental do estereótipo e do ritmo em relação à circulação de dizeres sustentados por préconstruídos morais. Observamos que os sentidos que se constituem nos discursos dos folhetos nordestinos circulam de maneira amena pelo entrecruzamento que há entre ritmo e estereotipia, entrecruzamento este que produz o efeito de ludicidade aos preceitos morais que estão presentes na discursividade do cordel.

Essa compreensão acerca do funcionamento e dos efeitos de sentido do jogo entre estereotipia e ritmo produzindo um efeito de ludicidade, nos possibilitaram ver que o cordel é um modo de textualização no qual discursos que causariam polêmica entre os interlocutores, devido à forte presença de elementos morais - como é o caso da mulher obediente e passiva ao marido ou da coroa - são ouvidos por todos com um tom de graça e de brincadeira. 
Assim, quando estivermos lendo, ou melhor ainda, ouvindo um simples cordel, não é apenas uma história engraçadinha que estamos vendo e sim um jogo complexo e interessante de linguagem que torna tal história, repleta de moral e muitas vezes coercitiva socialmente, engraçada.

\section{BiBLIOGRAFIA}

ABREU, Márcia - Histórias de cordéis e folhetos, Campinas: E d. Mercado das letras, 1999.

AMOSSY, R. \& HERSCHERBERG Pierrot, A. - S téréotipes et clichés, Paris : Ed. Nathan, 1997.

CURRAN, M. J. - A Literatura de Cordel: Antes e Agora - in Hispania, Vol. 74, no. 3, S pecial Issue Devoted to Luso-B razilian Language, Literature and Culture, 1991, pp. 570-576.

LONDRES, Maria J osé Fialo - C ordel: do encantamento às histórias de luta, São Paulo, Ed. Duas Cidades, 1983.

MESCHONNIC, H. - Critique du Rythime antropologie historique du langage - Paris, Ed. Verdier, 1982.

ME YE R, Marlyse - Autores de cordel, São Paulo, Abril E ducação, 1980.

OLIVE IRA, Maria Francinete - A representação da mulher na literatura de cordel, PUC Rio G rande do Sul, dissertação de mestrado, 1981.

ORLANDI, E. Análise de discurso, princípios e procedimentos, C ampinas, Ed. Pontes, 2002.

PÊCHEUX, M. - Semântica e Discurso uma crítica à afirmação do óbvio, Campinas, Ed. Unicamp, 1975.

\section{FolHetos UTILIZADOS COMO MATERIAL DE PESQUisA}

BATIS TA, A. Nascimento, vida e morte de uma coroa. s. d. A mulher do Compadre Nicolau, s. d.

CAVALCANTE, R. C. A língua da mulher faladeira. s. d. QUARE SMA, A. Discussão de Amaro Quaresma e J osé B atista. s. d. SANTOS, J. Os sinais das mulheres, s. d. SANTOS, F. S. A mulher que se casou dezoito vezes, s.d. SILVA, J. B. O valor da mulher. s. d. 
ABSTRACT: This article, supported by the Materialist Discourse Analysis theory, presents the analysis of the role of stereotypes and rhythm in Cordel Literature. We used booklets with women stereotypes as research material to constitute the corpus of this work, which are part of the C ordel Literature archive from CE DAE/ UNIC AMP. In this article we comprehend that the intersection between rhythm and stereotype produces a ludic effect which enables the moral in cordel discourse to have an easier circulation among the public.

Keywords: Discourse Analysis; rhythm, stereotype, corde 